\title{
Fluid transport by rabbit preimplantation blastocysts in vitro
}

\author{
R. M. Borland, J. D. Biggers and C. P. Lechene \\ Laboratory of Human Reproduction and Reproductive Biology, \\ Department of Physiology, Harvard Medical School, 45 Shattuck Street, \\ Boston, Massachusetts 02115, U.S.A.
}

The large expansion of the rabbit blastocyst between the $3 \mathrm{rd}$ and 7 th day post coitum (p.c.) is due to the accumulation of fluid in the blastocoele cavity (Daniel, 1964). $\mathrm{Na}^{+}, \mathrm{Cl}^{-}$and $\mathrm{HCO}_{3}{ }^{-}$appear to be actively transported across the trophectoderm into the blastocoele (Cross, 1973, 1974) and water moves passively secondary to $\mathrm{NaCl}$ accumulation (Borland, Biggers \& Lechene, 1976; see also review by Borland, 1977). The trophoblast cell is physiologically polarized in that $\mathrm{Na}$ is transported into the blastocoele by $\mathrm{Na} / \mathrm{K}$ pumps $\left(\mathrm{Na}^{+}-\mathrm{K}^{+}\right.$ATPase, E.C. 3.6.1.3) located on the juxtacoelic plasma membrane of the trophoblast cells (Biggers, Borland \& Lechene, 1977). This functional polarity is also reflected by the anatomical polarity of the trophectoderm. Membrane junctional complexes are located at the apices of the trophoblast cell and are adjacent to fluid-filled intercellular spaces that face the blastocoele cavity (Gamow \& Daniel, 1970; Enders, 1971; Hastings \& Enders, 1975; Ducibella, Albertini, Anderson \& Biggers, 1975). Diamond \& Bossert (1967) have proposed that such closed-end channels may be the site of active solute transport that creates local standing osmotic gradients which cause water flow across epithelia.

Two models have been invoked to explain the mechanism by which water is passively moved across epithelial membranes coupled to active ion transport. These are the double-membrane model of Curran \& McIntosh (1962) and Patlak, Goldstein \& Hoffman (1963), and the local osmotic standinggradient model of Diamond (1964) and Diamond \& Bossert (1967). Diamond (1964) pointed out that if the local osmosis model is correct the osmolality of the transported fluid should directly reflect the osmolality of the bathing medium. In contrast, if the double-membrane model is correct the osmolality of the transported fluid will vary; it will be hypertonic if the bathing medium is relatively dilute and hypotonic if it is relatively concentrated, and only one particular medium will be associated with isotonic transport. Na pumps on the juxtacoelic membrane of the trophoblast could provide the local osmotic gradient required in the standing-gradient model. If local osmosis occurs, then the transported fluid should be isotonic or hypertonic to the bathing solution. However, previously published reports that rabbit blastocysts accumulate hypotonic fluid in vivo on Days 7 and 8 post coitum (Tuft \& Böving, 1970) and in vitro on Day 5 post coitum (Gamow \& Daniel, 1970) are inconsistent with this model. The present experiments were therefore performed to determine the osmotic relationship between blastocoelic fluid and its environment and to gain evidence for the role of local osmosis in fluid transport by the rabbit blastocyst.

Blastocysts were flushed from the uterine horns of New Zealand White rabbits on the 5th day p.c. using Kreb's-Ringer bicarbonate with $0.1 \%$ glucose (KRBG) warmed to $37^{\circ} \mathrm{C}$. KRBG contains (mM): $\mathrm{NaCl}, 119 ; \mathrm{KCl}, 4 \cdot 74 ; \mathrm{CaCl}_{2}, 1 \cdot 71 ; \mathrm{KH}_{2} \mathrm{PO}_{4}, 1 \cdot 19, \mathrm{MgSO}_{4} \cdot 7 \mathrm{H}_{2} \mathrm{O}, 1 \cdot 19 ; \mathrm{NaHCO}_{3}, 25 ;$ and glucose, $5 \cdot 55$. The embryos were immediately placed in a modified F10 medium (Van Blerkom \& Manes, 1974; Borland et al., 1976) consisting of F10 (Microbiological Associates) buffered with 0.02 M-N-2-hydroxyethylpiperazine-N'-2-ethanesulphonic acid (HEPES: Calbiochem) adjusted to pH 7·4 with $1 \mathrm{~N}-\mathrm{NaOH}$ and containing $20 \%$ fetal calf serum (Microbiological Associates). The blastocysts were then collapsed by puncturing them with micropipettes, $6-8 \mu \mathrm{m}$ diameter, and withdrawing the blastocoele fluid. After collapse, the blastocysts were incubated for $24 \mathrm{~h}$ in $2 \mathrm{ml}$ of an experimental medium in a Falcon No. 3033 tissue-culture tube at $37.5^{\circ} \mathrm{C}$ in a high humidity atmosphere of $5 \% \mathrm{CO}_{2}$ in air. Five experimental media were used: they consisted of equal volumes of modified F10 medium and $\mathrm{KRBG}$ in which the concentrations of $\mathrm{NaCl}$ were varied. The mixture was supplemented with $20 \%$ fetal calf serum. At the end of the incubation period all of the blastocysts had re-expanded to 
fill the zona pellucida and appeared normal. Samples of blastocoele fluid were collected by micropuncture and analysed for $\mathrm{Na}, \mathrm{Cl}, \mathrm{K}, \mathrm{Ca}, \mathrm{Mg}, \mathrm{S}$ and $\mathrm{P}$ by electron probe microanalysis according to the methods previously described (Borland et al., 1976). The osmolalities of blastocoele fluid and of the culture medium in which the embryos had been incubated were both measured, in picolitre volumes, immediately after collection in a modified Ramsay-Brown (1955) osmometer by using a quartz thermometer.

Four rabbits were used in the experiment, the blastocysts from each rabbit providing one replicate. Because the number of blastocysts recovered varied from rabbit to rabbit the number of blastocysts allotted to each treatment varied between replicates: some treatments were allotted one blastocyst and others two and a total of 32 blastocysts was studied. The data were statistically analysed, after assuming an unbalanced 2-way crossed classification with interaction, by the computational procedures described by Searle (1971). Weighted means, and their variances, of the treatment effects were computed. The computations were performed with the untransformed data, and after transformation to natural logarithms. The conclusions were the same in both scales and the results are therefore presented as the untransformed data.

Table 1. The osmolalities of rabbit blastocoele fluid and bathing media and the concentrations of $\mathrm{Na}, \mathrm{Cl}, \mathrm{K}, \mathrm{Ca}, \mathrm{Mg}$, $S$ and $P$ in the blastocoele fluid that accumulated after incubation for $24 \mathrm{~h}$ in media containing different concentrations of $\mathrm{NaCl}$

Deviation of conc. of $\mathrm{NaCl}$ (mM) from control medium

$\begin{array}{lllll}-40 & -20 & 0 & 20 & 40\end{array}$

Osmolalities (mosmol)
Blastocoele fluid (10 d.f.)*
Medium (12 d.f.)*
Elements (mM) $(12$ d.f.)
$\mathrm{Na}$
$\mathrm{Cl}$
$\mathrm{K}$
$\mathrm{Ca}$
$\mathrm{Mg}$
$\mathrm{S}$
$\mathrm{P}$

$\begin{array}{cclll}235 \pm 2 & 273 \pm 3 & 304 \pm 2 & 339 \pm 2 & 375 \pm 2 \\ 231 \pm 4 & 267 \pm 4 & 295 \pm 4 & 332 \pm 4 & 370 \pm 4 \\ & & & & \\ 110 \pm 1 & 130 \pm 1 & 151 \pm 1 & 174 \pm 1 & 191 \pm 1 \\ 75 \pm 1 & 102 \pm 1 & 124 \pm 1 & 156 \pm 1 & 176 \pm 1 \\ 6.13 \pm 0.26 & 4.08 \pm 0.26 & 4.64 \pm 0.24 & 3.60 \pm 0.24 & 3.61 \pm 0.26 \\ 0.44 \pm 0.05 & 0.41 \pm 0.05 & 0.51 \pm 0.05 & 0.68 \pm 0.05 & 0.77 \pm 0.05 \\ 0.22 \pm 0.05 & 0.25 \pm 0.05 & 0.19 \pm 0.05 & 0.20 \pm 0.05 & 0.58 \pm 0.05 \\ 1.70 \pm 0.11 & 1.60 \pm 0.11 & 1.79 \pm 0.10 & 1.91 \pm 0.10 & 2.94 \pm 0.11 \\ 2.63 \pm 0.16 & 3.52 \pm 0.16 & 3.02 \pm 0.15 & 4.31 \pm 0.15 & 4.51 \pm 0.16\end{array}$

All S.E.M. were obtained from the pooled error mean squares of the analyses of variance.

* The degrees of freedom differ between the two parameters because the data on the osmolalities of the media were analysed as a two-way balanced classification with one observation per cell, while the data on the blastocoele fluid were analysed as a two-way classification with interaction with unequal numbers per cell.

The results are summarized in Table 1. The osmolality of the blastocoele fluid that accumulates during re-expansion is very similar to that of the bathing medium. Nevertheless, there is a suggestion that a small osmotic gradient exists across the trophectoderm at all concentrations of $\mathrm{NaCl}$ in the medium. An estimate of this gradient when two blastocysts were incubated together is given by

$$
\Delta_{2}=0.5\left(B_{1}+B_{2}\right)-M
$$

and when a blastocyst was incubated alone by

$$
\Delta_{1}=B-M
$$

where $B$ is the osmolality of blastocoele fiuid and $M$ is the osmolality of the medium. It is not clear what relative weights should be attached to $\Delta_{1}$ and $\Delta_{2}$, and the data have been analysed assuming that they carry equal informational value. An analysis of variance shows that the mean gradient does not vary between the media. The overall mean gradient was calculated to give an estimate of $8.28 \mathrm{mosmol}$. (S.E.M. 2.09, d.f. 12). This gradient is statistically significant $(P=\mathbf{0 . 0 0 2})$. The relationship between the osmolality of the blastocoele fluid and osmolality of the culture medium is shown graphically in Text-fig. 1. Rabbit blastocoele fluid is therefore slightly hypertonic to the bathing medium over a 
wide range of the chemical potential of the bathing medium. These observations are consistent with the data of Tuft \& Böving (1970) showing that rabbit blastocoele fluid in vivo is slightly hypertonic to uterine fluid on Days 5 and 6 p.c., but do not support the claim by Gamow \& Daniel (1970) that blastocysts in culture accumulate an hypotonic blastocoele fluid. As shown in Text-fig. 1 the osmolality of blastocoele fluid maintains a constant, nearly isosmotic relationship to the medium from 230 to 370 mosmol. The data are therefore consistent with blastocoele fluid accumulation occurring by local osmosis into closed channels, such as the lateral intercellular spaces (Diamond \& Bossert, 1967). A number of other epithelia, such as rabbit gall bladder (Diamond, 1964), insect Malpighian tubule (Maddrell, 1969) and rat jejunum (Lee, 1968), are capable of isosmotic or near isosmotic fluid transport, and exhibit a pattern of fluid transport similar to that shown in Text-fig. 1.

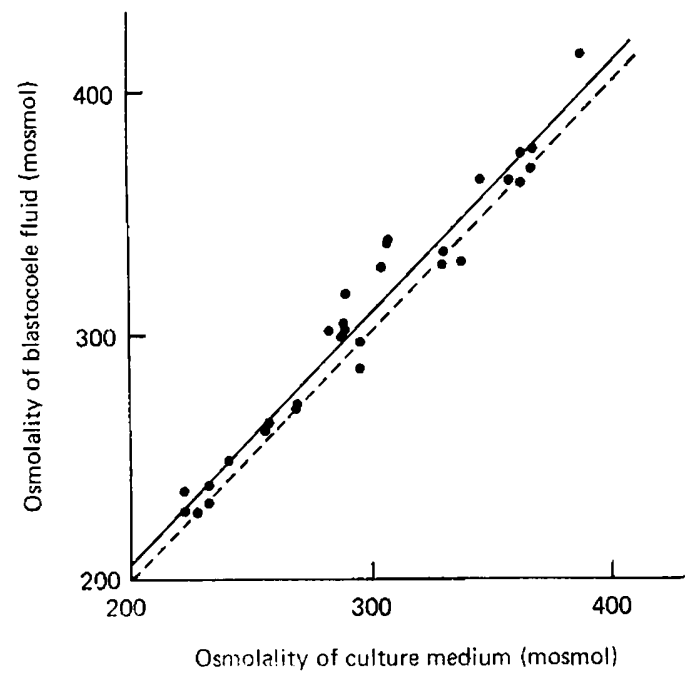

Text-fig. 1. The osmolality of rabbit blastocoele fiuid plotted against the osmolality of culture medium. Rabbit blastocysts ( 5 days p.c.) were incubated for $24 \mathrm{~h}$ in culture medium for which the osmolality was altered by the addition or deletion of $\mathrm{NaCl}$ from the standard media. The solid line $(\longrightarrow)$ is the linear regression of the data and has a unit slope. The dashed line (---) represents isosmotic fiuid transport. The displacement of the solid line from the dashed line is significant $(P=0.002)$ and indicates slightly hypertonic fluid transport.

Analyses of variance of the concentrations of $\mathrm{Na}, \mathrm{Cl}, \mathrm{K}, \mathrm{Ca}, \mathrm{Mg}, \mathrm{S}$ and $\mathrm{P}$ in the blastocoele fluids showed that the means varied significantly with changes in the concentration of $\mathrm{NaCl}$ in the bathing medium. The regression of blastocoele fluid $\mathrm{Na}$ concentration on the change of $\mathrm{NaCl}$ concentration in the medium has only a linear component and is highly significant. Its value of 1.04 is not significantly different from 1 . The regression of blastocoele fluid $\mathrm{Cl}$ concentration on the change of $\mathrm{NaCl}$ concentration in the medium has a highly significant linear component that is significantly greater than 1, but it also has other significant non-linear components. The slope of the linear component of the regression of blastocoele fluid $\mathrm{Ca}$ on the change of $\mathrm{NaCl}$ concentration in the medium is highly significant but small. The physiological reason for this trend is unknown. The linear regressions of blastocoele fluid $\mathrm{K}, \mathrm{Mg}, \mathrm{S}$ and $\mathrm{P}$ on the change of $\mathrm{NaCl}$ concentration in the medium deviated significantly from linearity. Although the means were significantly different, the variation was relatively small and possibly of no physiological significance.

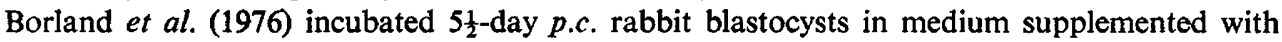
various amounts of sucrose to which rabbit trophectoderm is highly impermeable. Electron probe microanalysis of the blastocoele fluid under these conditions showed that blastocoele fluid concentrations of $\mathrm{Na}$ and $\mathrm{Cl}$ each increase $1 \mathrm{~mm}$ in response to every $2 \mathrm{mM}$ of sucrose gradient across the trophectoderm. Because $\mathrm{NaCl}$ dissociates to form two osmotically active particles, the relationship 
Table 2. The regression of concentrations of $\mathrm{Na}, \mathrm{Cl}$ and $\mathrm{Ca}$ in rabbit blastocoele fluid when the concentration of $\mathrm{NaCl}$ in the incubation medium is changed

\begin{tabular}{lcrr}
\hline & $\mathrm{Na}$ & $\mathrm{Cl}$ & $\mathrm{Ca}$ \\
\hline $\begin{array}{l}\text { Linear regression } \\
\text { Standard error }\end{array}$ & +1.04 & +1.28 & +0.0047 \\
$\begin{array}{l}\text { Tests of significance } \\
\chi^{2}[1]: \text { linear regression }\end{array}$ & 0.02 & 0.02 & 0.0001 \\
$\begin{array}{l}\chi^{2}[3] \text { : departures from linear } \\
\quad \text { regression }\end{array}$ & $2150^{* * *}$ & $6827^{* * *}$ & $37 * * *$ \\
\hline
\end{tabular}

The Iinear regression and the tests of significance were calculated by using the formulae given by Hatheway \& Wiiliams (1958). ***P<0.001.

of the $\mathrm{Na}$ concentration in blastocoele fluid to medium $\mathrm{NaCl}(1 \mathrm{~mm} \mathrm{Na}$ accumulated in the blastocoele in response to every $1 \mathrm{~mm}$ of $\mathrm{NaCl}$ gradient) (Table 2) is similar to that between the concentration of $\mathrm{Na}$ in the blastocoele fluid and the concentration of sucrose in the medium. In contrast, the data in Table 2 indicate that significantly more $\mathrm{Cl}$ than $\mathrm{Na}$ is accumulated in blastocoele fluid for every incremental change in medium $\mathrm{NaCl}$ concentrations. Since $\mathrm{HCO}_{3}{ }^{-}$and $\mathrm{Cl}^{-}$are the predominant anions in blastocoele fluid (Lutwak-Mann, 1962; Lewis \& Lutwak-Mann, 1954; Smith, 1970; Borland et al., 1976), the greater rise in $\mathrm{Cl}$ concentration than in $\mathrm{Na}$ concentration may reflect a decreasingly important bicarbonate accumulation in the presence of increasing medium $\mathrm{Cl}$ concentrations. Further studies are necessary, however, to determine the relationship between $\mathrm{Cl}^{-}$and $\mathrm{HCO}_{3}{ }^{-}$ transport by rabbit blastocysts. $\mathrm{HCO}_{3}{ }^{-}$appears to accumulate in rabbit blastocoele fluid by some active transport process but the exact mechanism(s) involved is not known (Cross, 1974; review by Borland, 1977).

The work reported in this paper has been supported by grants from the Ford Foundation (7200369), the Rockefeller Foundation (RF-65040), the NIH (R01-HL-15552-03 and P07-RR00679-02) and the NICHHD (HD-06916-01A3). We are indebted to Mrs Mary Forte for preparation of typescripts.

\section{References}

Biggers, J.D., Borland, R.M. \& Lechene, C.P. (1977) Ouabain-sensitive fluid accumulation and ion transport in rabbit blastocysts. J. Physiol., Lond. (in press).

Borland, R.M. (1977) Transport processes in the mammalian blastocyst. In Development in Mammals, Vol. 1, pp. 31-67. Ed. M. H. Johnson. North-Holland Publ. Co., Amsterdam.

Borland, R.M., Biggers, J.D. \& LeCheNe, C.P. (1976) Kinetic aspects of rabbit blastocoele fluid accumulation: an application of electron probe microanalysis. Devl Biol. 50, 201-211.

Cross, M.H. (1973) Active sodium and chloride transport across the rabbit blastocoele wall. Biol. Reprod. 8, 566-575.

Cross, M.H. (1974) Rabbit blastocoele bicarbonate: accumulation rate. Biol. Reprod. 11, 654-662.

Curran, P.F. \& McIntosh, J.R. (1962) A model system for biological water transport. Nature, Lond. 193, 347-348.

DANIEL, J.C. (1964) Early growth of rabbit trophoblast. Am. Nat. 98, 85-98.

DIAMOND, J.M. (1964) The mechanism of isotonic water transport. J. gen. Physiol. 48, 15-42.
DiAmond, J.M. \& BoSSERT, W.H. (1967) Standing gradient osmotic flow. A mechanism for coupling of water and solute transport in epithelia. J. gen. Physiol. 50, 2061-2083.

Ducibella, T., Albertini, D.F., Anderson, E. \& Biggers, J.D. (1975) The preimplantation mammalian embryo: characterization of intercellular junctions and their appearance during development. Devl Biol. 45, 231-250.

ENDERS, A.C. (1971) The fine structure of the blastocyst. In The Biology of the Blastocyst, pp. 71-94. Ed. R. J. Blandau. University of Chicago Press.

GAMOW, E. \& DANIEL, J.C. (1970) Fluid transport in the rabbit blastocyst. Wilhelm Roux Arch. EntwMech. Org. 164, 261-278.

Hastings, R.A. \& Enders, A.C. (1975) Junctional complexes in the preimplantation rabbit embryo. Anat. Rec. 181, 17-34.

Hatheway, W.H. \& Williams, E.J. (1958) Efficient estimation of the relationship between plot size and the variability of crop yields. Biometrics 14, 207-222.

LEE, J.S. (1968) Isosmotic absorption of fluid from rat jejunum in vitro. Gastroenterology 54, 366-374. 
LEWIS, P.R. \& LUTWAK-MANN, C. (1954) The content of sodium, potassium and chloride in rabbit blastocysts. Biochim. biophys. Acta 14, 589-590.

LUTWAK-MANN, C. (1962) Glucose, lactic acid and bicarbonate in rabbit blastocyst fluid. Nature, Lond. 193, 653-654.

MADDRELL, S.H.P. (1969) Secretion by the Malpighian tubules of Rhodnius. The movement of ions and water. J. exp. Biol. 51, 71-97.

Patlak, C.S., Goldstern, D.A. \& Hoprman, J.F. (1963) The flow of solute and solvent across a twomembrane system. J. theor. Biol. 5, 426-442.

Ramsay, J.A. \& Brown, R.H.J. (1955) Simplified apparatus and procedure for freezing-point determinations upon small volumes of fluid. $J$. scient. Instrum. 32, 372-375.

SeArLe, S.R. (1971) Linear Models. Wiley, New York.

SMITH, M.W. (1970) Active transport in the rabbit blastocyst. Experientia 26, 736-738.

TUFT, P.H. \& Böving, B.G. (1970) The forces involved in water uptake by the rabbit blastocyst. $J$. exp. Zool. 174, 165-172.

VAN Blerkom, J. \& MANes, C. (1974) Development of preimplantation rabbit embryos. II. A comparison of qualitative aspects of protein synthesis. Deol Biol. 40, 40-51.

Received 14 January 1977 